\title{
The role of SHBG and LPL gene polymorphism in the development of age-related hypogonadism in overweight men: Literature review
}

\author{
Merkhat Akkaliyev ${ }^{1}$, Nurlan Aukenov ${ }^{2}$, Meruyert Massabayeva ${ }^{3}$, Bakytbek Apsalikov ${ }^{4}$, Saule Rakhyzhanova ${ }^{5}$, \\ Muratkhan Kuderbaev ${ }^{1}$
}

${ }^{1}$ Department of Surgery Disciplines, Semey Medical University, Semey, Kazakhstan

${ }^{2}$ Department of Health and Human Resources, Ministry of Healthcare of the Republic of Kazakhstan, Semey, Kazakhstan

${ }^{3}$ Scientific-Research Laboratory Center, Semey Medical University, Semey, Kazakhstan

${ }^{4}$ Department of Family Medicine, Semey Medical University, Semey, Kazakhstan

${ }^{5}$ Department of Normal Physiology, Semey Medical University, Semey, Kazakhstan

Received: 2021-07-14.

Accepted: 2021-09-13

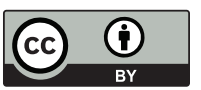

This work is licensed under a Creative Commons Attribution 4.0 International License

\section{J Clin Med Kaz 2021; 18(5):11-17}

Corresponding author:

Merkhat Akkaliyev.

E-mail: merchat_72@mail.ru;

ORCID: 0000-0003-3122-7411

\begin{abstract}
Testosterone is the main male hormone responsible for the formation and maintenance of male sex characteristics and the sexual performance of men. With age testosterone levels decrease which is a natural physiological process. But the timing of age-related hypogonadism progress has individual differences. Physiological processes occurring in the body of an aging man are due to genetic, population and individual features of genes and their mutations leading to genetic polymorphism. Gene polymorphism is represented mainly by single nucleotide substitutions that are SNP (single nucleotide polymorphism). Sex hormone binding globulin (SHBG) and lipoprotein lipase (LPL) genes are important links in the synthesis and transport of testosterone in male body as well as in the development of androgen deficiency. This review discusses the role of polymorphic variants of SHBG and $L P L$ genes in the early development of age-related hypogonadism in overweight men.
\end{abstract}

Key words: age-related hypogonadism in men, obesity, polymorphism of SHBG and LPL genes, overweight, erectile dysfunction

\section{Introduction}

The task of modern medicine implies diagnosis, prevention and treatment of diseases of male body and the capabilities of genomic medicine are aimed at completing this task. Testosterone as the main male hormone is responsible for maintaining male sexual characteristics and sexual capabilities of men [1]. With age, the level of testosterone decreases, but it is a natural physiological process [2,3]. There is a decrease in the testicles and libido, while adipose tissue increases [4]. But the time of occurrence of hypogonadism in everyone has individual peculiarities [5]. The physiological processes occurring in the body of an aging man are due to the genetic, population and individual characteristics of genes and their mutations. These mutations lead to genetic polymorphism that is represented mainly by single nucleotide substitutionsSNP (single nucleotide polymorphism). In recent years, the method of genome-wide association search (GWAS) has been widely used to search for marker-genes [6]. Both the synthesis of testosterone and its transportation to target cells is equally vital for maintaining a constant level for a male body. One of the important parameters for the transport of testosterone to target tissues is the level of globulin-binding sex hormone (SHBG) [2,7].

Sex hormone binding globulin (SHBG) is synthesized and secreted into the bloodstream by hepatocytes [8]. SHBG binds biologically active androgens, and regulates their bioavailability for target tissues $[9,10]$. With an increase in the age of a man, there is a growth in the concentration of SHBG, that results in a decrease of free testosterone [11]. The change in the level of SHBG depends on its genetic variants [12]. A decrease in testosterone is always accompanied by excess weight, which is a predictor of obesity and metabolic syndrome. 
Overweight and hypogonadism are mutually reinforcing conditions and there is no full explanation in medicine what is primary [13-15]. Some authors consider a decrease in testosterone to be secondary, since a decrease in body weight leads to a normalization of testosterone indicators [16]. Others believe that one of the reasons for the decrease in testosterone in obese patients is the activity of aromatase of excess adipose tissue [17-19].

Studies have proved that low concentrations of total testosterone are associated with an unfavorable lipid profile, which includes high levels of triglycerides and LDL and low levels of HDL [20].

In the metabolism of lipids, three key points such as absorption, transport and assimilation by tissues can be distinguished and assimilation begins with the action of lipoprotein lipase (LPL), which breaks down triglycerides into fatty acids and glycerin. Thus, LPL is one of the essential factors of lipid metabolism [21,22]. Testosterone also inhibits the expression of LPL in adipocytes, the main enzyme that regulates the accumulation of triglycerides in the fat cell. With a decrease in the level of testosterone, the number of adipocytes increases. This fact causes a violation of the metabolism of free fatty acids and excessive fat accumulation with a decrease in active muscle mass [23-26]. In the presence of a LPL gene mutation hypertriglyceridemia and dyslipidemia develop, contributing to obesity, development of metabolic syndrome, coronary heart disease and hypertension [27,28].

Predictive medicine as the central direction of molecular medicine implies pre-symptomatic detection of persons with a high risk of developing hereditary diseases. However, the genetic risk factors for an early decrease in testosterone and factors that reduce it, such as obesity, diabetes mellitus and lipid metabolism disorders, have not been sufficiently studied and there are gaps in this direction. The search for new ideas, the optimization of existing scientific experience in the diagnosis of polymorphism of the genes of SHBG and LPL and the development of preventive measures for the age-related hypogonadism and obesity in men was the main reason to conduct literary review study.

The study is aimed at analyzing published works on the polymorphism of the genes of SHBG and LPL in the occurrence of early hypogonadism and obesity in men in Kazakhstan, in neighboring countries and in the world.

\section{Searching strategy}

To accomplish the task, we have carried out analysis of scientific publications in evidence-based medicine databases (PubMed, CochraneLibrary, ResearchGate, Webofscience, GoogleScholar, Paragraph Medicine, ScienceDirect).

\section{Data sources}

Inclusion criteria: studies of high methodological quality (meta-analyzes, systematic reviews, randomized controlled and cohort studies); also we took into account the publications on the results of case-control and cross-sectional studies with statistically proven findings in English and Russian.

Exclusion criteria: articles describing single cases and personal messages with no evidence base, abstracts, mass media and advertising articles.

Search depth: 10 years (2010 to 2020). 70 relevant papers reflecting the characteristics of the problem were accepted for the review content.

The keywords for the search: age-related hypogonadism in men, obesity, polymorphism of SHBG and LPL genes, overweight, erectile dysfunction.
As this was a systematic review, ethical approval and consent was not required to participate.

\section{Findings}

One of the most captivating works in the study of the genetic theory of early hypogonadism in men is the manuscript by Ohlsson (2011). This study identified two SHBG gene loci located at 17p13 (SNP: rs 12150660 and rs 6258) and at Xp22 (SNP: rs 5934505), which were significantly associated with serum testosterone levels. An r 6258 is the first reported SHBG polymorphism that affects the binding of testosterone to SHBG and the free fraction of testosterone and therefore may influence the calculation of free testosterone. But this study gives a modest result and explains the small percentage (0.6-2.3) interindividual variability in testosterone levels. Additional variants of the sequence of alleles that affect the level of testosterone are probably not to have been identified and are yet to be discovered [29].

Based on Olson's experience, Chinese scientists conducted a similar study in the Chinese population. Yao-ping Chen (2015) and colleagues conducted a large-scale study in six regions of China: Hebei, Shanxi, Guangdong, Hubei, Jiangsu and Guizhou. The study group included 6,898 men aged 18 to 89 years. The aim of this study was to determine whether four SNP loci (rs12150660, rs727428, rs5934505, and rs10822184) are associated with low testosterone levels, hypogonadism, or obesity in the Chinese Han population. Obesity is one of the common causes of hypogonadism in older men [13]. According to this study, the frequency of the rs12150660 allele in the Chinese population is very rare, although in other studies this allele was correlated with the level of testosterone and SHBG in groups of European origin [29-32]. The results of this study have convincingly proved rs 5934505 to correlate with low testosterone levels in the Chinese population, as well as in Europeans, which creates the prerequisites for an early decrease in serum testosterone levels and the early development of agerelated hypogonadism in men in the Chinese population.

In contrast to the European population, genetic analysis demonstrates that rs727428 is not associated with serum SHBG and testosterone levels in Chinese men. Rs10822184 significantly correlated with BMI in the Chinese population, which accordingly increased the risk of developing overweight and obesity. This study proves that loci rs12150660, rs727428, and rs10822184 differ between the Chinese and European populations. However, further large and functional studies are needed to confirm our results [33].

In 2019, Daniel Castellano-Castillo and colleagues studied the SHBG gene polymorphism (rs1799941) in young men. The study involved 212 men aged 30 to 45 years, with obesity (BMI above $30 \mathrm{~kg} / \mathrm{m} 2$ ) and no history of diabetes mellitus. In the course of scientific research, it was found that the rs1799941 polymorphism in young obese and hypogonadal men was associated with SHBG levels and, therefore, could determine the free testosterone fraction. This study proves that rs1799941 of the SHBG gene determines the genetic factor for hypogonadism. It indirectly promotes obesity, which will undoubtedly be of clinical interest in the correction of hypogonadism in representatives with this polymorphism in the phenotype [34].

Guangfu Jin et al, in their studies identified a new 10q21 DNA locus that was associated with serum androgen levels using GWAS in 3225 European males, and confirmed two loci at $17 \mathrm{p} 13$ and Xp22 reported by Ohlsson et al. [29]. 
In addition to confirming the association of two known loci associated with serum testosterone levels (rs727428 in SHBG; rs5934505 in FAM9B), it was possible to identify a new locus JMJD1C in 10q21, which was associated with serum testosterone levels (rs10822184). There was also a way to prove that rs727428 was associated with serum DHT levels. However, some limitations of this study should be noted. First, $10 \mathrm{q} 21,17 \mathrm{p} 13$, and Xp22 variants account for only a small fraction of the total observed variance in serum testosterone and dihydrotestosterone levels. This suggests that there may be other genetic determinants of serum androgen levels that remain unknown. Second, the statistical power of this study has relative limitations, especially for assessing the association between SNP and prostate cancer risk, given that among 1,644 people in the placebo group, there were only 410 cases of prostate cancer and 124 cases of aggressive disease. Thus, future studies with a large sample size may be required in other populations to validate and extend our findings.

These results allow us to take a new look at the regulation of circulating androgen levels and may have clinical significance for androgen-related diseases [35].

Despite some progress in the personalized management of patients, there are many unclear points, in particular, the influence of genetic factors on the levels of reproductive hormones and the quality of sperm. Further studies of the genetic influence on the violation of reproductive physiology and the development of a personalized scheme taking into account the genetic profile of a man are needed to be conducted. In this direction, the work of Marina Grigorova (2017) is of special interest. The study has covered 578 men of reproductive age who were in an infertile marriage. All the men were recruited at the Andrology Hospital Center of the University of Tartu. All the study participants were born and lived in Estonia. In total, seven genetic variants in genomic DNA isolated from patients ' blood samples have been analyzed.

Of all the studied loci in the framework of our review, we were interested in a fragment of the SHBG study (rs1799941, rs727428, and rs6258). But the study did not reach statistical significance. Thus, the current data rule out a role for mutated SHBG in the predisposition to severe male factor infertility. Accordingly, none of the SNPs tested (rs1799941, rs727428, and rs6258) were significantly associated with testicular volume and total sperm count and concentration. This study excludes the role of SHBG polymorphism in the predisposition to male infertility [36].

Epidemiological studies have repeatedly found an association between low serum testosterone levels in men and subsequent development of central obesity, increased insulin concentration, metabolic syndrome, and diabetes. These studies are certainly associated with the LPL gene $[37,38]$.

The state of hypoandrogenism in men is associated with insulin resistance that is a predictor of diabetes mellitus. According to the world literature review, the expected number of patients with diabetes mellitus by 2030 worldwide may reach 439 million; about $90 \%$ of these patients will have type 2 diabetes [39].

Sex hormone binding globulin (SHBG) is the main transport protein for testosterone and estradiol. However, recent research suggests that SHBG has additional biological significance. Low concentrations of SHBG are associated with an increased risk of type 2 diabetes mellitus [40]. Lifestyle and genetic factors may further contribute to the underlying physiological causes responsible for the pathophysiology of type 2 diabetes. More than 36 genes have been identified that are responsible for the risk of type 2 diabetes. All these genes account for only about $10 \%$ of the total genetic factors of the disease $[41,42]$.

Tarhouny (2015) together with colleagues conducted a study of the relationship of SHBG polymorphism (rs6257 and rs6259) with the risk of diabetes mellitus and its effect on the level of sex hormones in the blood of men with proven type 2 diabetes. The study involved 185 male patients with type 2 diabetes mellitus observed in the Zagazig Diabetic Clinic, a control group composed of Egyptian men with normal fasting blood glucose levels. The owners of the rs6257 and rs6259 polymorphic variants had a significant decrease in SHBG, which led to a significant decrease in total testosterone levels and an increase in estradiol levels compared with the control group. This means that carriers of this phenotype have a high risk of developing type 2 diabetes mellitus $[43,41]$.

This condition may contribute to a greater accumulation of visceral fat, which enhances insulin resistance and diabetes by increasing inflammatory cytokines [44]. Sex hormone binding globulin may be an important target for type 2 diabetes risk stratification and early intervention. This fact has been repeatedly confirmed by many authors [45-48]. Obesity and metabolic syndrome are often the result of hypogonadism and SHBG mutations, but this cannot be considered in isolation. Most of the LPL genetic defects cause hypertriglyceridemia and may be associated with obesity. Elevated blood triglyceride levels are one of the risk factors for cardiovascular disease $[49,50]$. At the moment, we cannot change a person's phenotype, but knowing his or her genomic data, we can predict the likelihood of developing a disease and effectively apply pharmacotherapy and diet therapy, which is the core principle of personalized medicine [51].

In this aspect, the study by T.B. Sentsova is worth considering. The study included 88 patients; the average body mass index (BMI) was 41.71 \pm 1.23 . Since metabolic changes in obese patients were mainly associated with changes in lipid metabolism, the dynamics of blood biochemical parameters was assessed for various polymorphic variants of LPL genes before and after the use of a standard version of a low-calorie diet. When studying the dynamics of blood biochemical parameters of carriers of various polymorphic markers of the LPL gene, it was found that a pronounced positive effect of diet therapy in obese patients was observed in carriers of the polymorphic $\mathrm{C} / \mathrm{C}$ variant of the LPL gene (Ser447Ter) [52,53]. The level of lipid metabolism in the blood is determined not only by genetic factors, but by the lifestyle that leads to overweight and obesity.

Jung-A Pyun et all conducted a study tracing the influence of lifestyle factors on lipid levels in Koreans with LPL polymorphism (rs263, rs271 and rs328). In the course of the study, it was found that the carriers of this polymorphism, with the consumption of calories in food (fats) had higher HDL levels. In representatives who did not have this polymorphism, this effect was not observed. Carriers of the same genotypes with alcohol consumption showed higher triglyceride levels. Given these data, it can be assumed that the appropriate lifestyle can be recommended in accordance with the type of LPL polymorphism for each person $[54,55]$.

Considering that LPL is related to overweight and obesity, in our search we have selected all genetic studies concerning LPL mutation in the relationship of lipid pathology and liver and pancreas diseases as a factor affecting BMI and testosterone levels in the blood of men.

Obesity is the most common predictor of metabolic 
syndrome associated with hypertriglyceridemia. A similar relationship can be traced in the relationship of type 2 diabetes.

P. Han (2020) in his scientific research has identified three mutations of the LPL gene (c.162C $>$ A, c.835C $>$ G and c. 1322 $+1 \mathrm{G}>\mathrm{A}$ ) in two unrelated Chinese patients with extremely rare and severe uhypertriglyceridemia. The functional analysis of the identified mutations has been carried out. As a result of this mutation of the LPL gene, partially or completely non-functional lipoprotein lipases are formed, which are unable to catabolize triglycerides into chylomicrons. Consequently, there is a gradual and progressive increase in chylomicrons, which leads to hypertriglyceridemia, diabetes mellitus, and the development of metabolic disorders [56]. These studies have been repeatedly carried out at different times by different authors [57-63].

It is a favorable fact that there are developments in gene therapy with an adeno-associated viral vector (AAV) for a lipoprotein lipase LPL (S447X) mutation in lipoprotein lipase deficiency. This pathology is characterized by severe hypertriglyceridemia and the risk of recurrent pancreatitis or other complications [64].

Lipoprotein lipase (LPL) plays a central role in lipoprotein metabolism, hydrolyzing the main fragments of triglycerides and circulating and low density lipoproteins (LDL). Researcher Rebhi L. (2012) also evaluated the effect of three polymorphisms HindIII, PvuII and Ser447Ter in the LPL gene on the lipid profile in Tunisian patients with coronary heart disease. Patients with genotypes HindIII TT, PvuII TC, and Ser447Ter had high levels of triglycerides, total cholesterol, and low density lipoproteins in plasma. The result of the study suggests that the HindIII polymorphism is considered as a marker of predisposition to coronary stenosis. Thus, there is an association between variants of the LPL gene and high levels of triglyceride, total cholesterol and LDL cholesterol, as well as low levels of HDL $[65,66]$

Violation of lipid metabolism requires a comprehensive study. It is worth mentioning that the weight loss after bariatric surgery affects the parameters of lipid metabolism the changes of which are due to genetic factors causing obesity. Sarzynski and his collaborators in Sweden conducted a 10-year patient monitoring of 1,771 Swedish obese patients after gastric ligation or bypass gastric anastomosis. The study demonstrated that the rs283 polymorphism was closely related to the baseline level of high-density lipoprotein (HDL-C) cholesterol in patients, and the level of HDL-C in the GG genotype groups was higher.

The amount of changes in high-density lipoprotein (HDL) cholesterol caused by weight loss might be of genetic character. We examined associations of eight candidate genes identified by genome-wide association studies with HDL-C at baseline and 10 years after bariatric surgery in a Swedish study of obese patients. None of the SNPs were significantly associated with changes in HDL levels associated with weight loss.

Thus, our results show that genetic variants contributing to the total level of HDL-C in persons with stable weight have little effect on individual variations in HDL-C changes in response to weight loss caused by bariatric surgery [67].

Lipoprotein lipase (LPL) plays a role in lipid homeostasis, and their gene mutation can be considered as prognostic genetic markers of metabolic syndrome.

In the study we aimed at assessing the possible associations of polymorphisms and LPL PvuII (+/-) with metabolic syndrome and signs (waist circumference and body mass index).

In the total sample of variants, representatives with a polymorphic variant of LPL (PvuII) had a large waist circumference and an increased BMI. The study results were featured by the significant effect of the LPL gene on HDL-C levels in the male population.

According to the results obtained, a mutated variant of the LPL gene can be factors of impairment of lipid status and predisposition to obesity, contributing to the development of metabolic syndrome, especially in men [68].

Similar to the previous research, the influence of the relationship between polymorphic LPL (Pvu II and Hind III) and carbohydrate consumption on the components of the metabolic syndrome in representatives of the Korean population has been studied (Kim Y., 2013). The study reveals that carriers of the polymorphic LPL variant (Hind III) have a high risk of developing metabolic syndrome and arterial hypertension. That undoubtedly needs to be taken into account during dynamic observation of this category of patients [69].

Lipoprotein lipase controls the distribution of fatty acids in body derived from circulating triglycerides, and plasma LPL concentration is closely related to intra-abdominal fat distribution.

Rui-Rui Gao investigated the effect of exercise on lipid and glucose metabolism. The researcher targeted at studying the effect of exercise on lipid metabolism in obese adolescents in the Han population with LPL gene polymorphism (rs283). In adolescents with the GG genotype, there is a more noticeable decrease in the percentage of intraperitoneal fat, insulin resistance and triglycerides during exercise. This fact indicates the possibility of early correction of lipid metabolism disorders by changing the lifestyle [70].

\section{Conclusion}

Analyzing the literature, we came to the conclusion that a genetic predisposition may contribute to the early onset of hypogonadism, overweight and obesity. But despite the great advances in decoding the human genome, there are no clear criteria in the genetic diagnosis of the early development of hypogonadism. Age-related hypogonadism is becoming an increasingly relevant condition, making it a public health problem. Its causes and physiological consequences at the individual level are still elusive. However, genetic predisposition at the individual level is the basis on which various other lifestyle and nutritional factors act, leading to its early development. Obesity does not occur without the presence of vulnerable genetic factors. Indisputably, further research in this area is needed to understand the pathogenesis of development in various population groups.

Summing up, we note that today there is no unified approach to processing the results of scientific research in the field of studying genetic predisposition, and, moreover, there is no unified assessment of the feasibility of using various preventive methods and its effectiveness in assessing the risk of hypogonadism. Therefore, a comprehensive and balanced approach is required both for the search for disease markers and for assessing their suitability for accurate risk prediction.

Disclosures: There is no conflict of interest for all authors.

Acknowledgements: None.

Funding: None. 


\section{References}

1. Nassar, G. N., \& Leslie, S. W.Physiology, Testosterone.StatPearls. 2019;95(1):122-131.http://www.ncbi.nlm.nih.gov/pubmed/30252384

2. Pashkova E. YU., Rozhdestvenskaya O,A. Vozrastnoy androgennyi deficit u mujchin: etiologia, klinika, diagnostic, lechenie. Andrologia I genitalnaya hirurgia. Age-related androgenic deficiency in men: etiology, clinical presentation, diagnosis, treatment. Andrology and genital surgery. 2015; 16(1):95-101. https://doi.org/10.17650/2070-9781-2015-1-95-101

3. Tyuzikov I.A., Kalinchenko S.Yu., Vorslov L.O., Tishova Yu.A. Mesto androgenogo defisita v klinişeskom portrete sovremenogo urologişeskogo pasienta. Andrologia i genitalnaya hirurgia. The place of androgen deficiency in the clinical portrait of a modern urological patient. Andrology and Genital Surgery. 2013; 14(3):48-57. https://doi.org/10.17650/2070-9781-2013-3-48-57

4. Lunenfeld, B., Mskhalaya, G., Zitzmann, M., Arver, S., Kalinchenko, S., Tishova, Y., \& Morgentaler, A. Recommendations on the diagnosis, treatment and monitoring of hypogonadism in men. The Aging Male. 2015; 18(1):5-15. https://doi.org/10.3109/13685538. 2015.100404

5. Venkatesan R, Viswanathan M. Obesity - Are we continuing to play the genetic "blame game"? Advances in Genomics and Genetics. 2016; 6:11-23 https://doi.org/10.2147/AGG.S52018

6. Beck, T., Shorter, T., \& Brookes, A. J. GWAS Central: A comprehensive resource for the discovery and comparison of genotype and phenotype data from genome-wide association studies. Nucleic Acids Research. 2020; 48(D1): D933-D940. https://doi.org/10.1093/ nar/gkz895

7. Avvakumov, G. V., Cherkasov, A., Muller, Y. A., \& Hammond, G. L. Structural analyses of sex hormone-binding globulin reveal novel ligands and function. Molecular and Cellular Endocrinology . 2010; 1(16):13-23. https://doi.org/10.1016/j.mce.2009.09.005

8. Hammond, G. L. Diverse Roles for Sex Hormone-Binding Globulin in Reproduction. BIOLOGY OF REPRODUCTION. 2011; 85:431-441. https://doi.org/10.1095/biolreprod.111.092593

9. Li, H., Pham, T., Mcwhinney, B. C., Ungerer, J. P., Pretorius, C. J., Richard, D. J., Mortimer, R. H., D’emden, M. C., \& Richard, K. Sex Hormone Binding Globulin Modifies Testosterone Action and Metabolism in Prostate Cancer Cells. International Journal of Endocrinology. 2016; 10:1-10. https://doi.org/10.1155/2016/6437585

10. Tint, A. N., Hoermann, R., Wong, H., Ekinci, E. I., MacIsaac, R. J., Jerums, G., Zajac, J. D., \& Grossmann, M. Association of sex hormonebinding globulin and free testosterone with mortality in men with type 2 diabetes mellitus. European Journal of Endocrinology. 2016; 174(1):59-68. https://doi.org/10.1530/EJE-15-0672

11. Firtser, S., Juonala, M., Magnussen, C. G., Jula, A., Loo, B. M., Marniemi, J. et al. Relation of total and free testosterone and sex hormone-binding globulin with cardiovascular risk factors in men aged 24-45 years. The Cardiovascular Risk in Young Finns Study. Atherosclerosis. 2012; 222(1):257-262. https://doi.org/10.1016/j.atherosclerosis.2012.02.020

12. Xita, N., \& Tsatsoulis, A. Genetic variants of sex hormone-binding globulin and their biological consequences. Mol. Cell. Endocrinol. 2010; 316(1):60-65. https://doi.org/10.1016/j.mce.2009.08.025

13. Fui, M. N. T., Dupuis, P., \& Grossmann, M. Lowered testosterone in male obesity: Mechanisms, morbidity and management. Asian $J$ Androl. 2014; 16(2):223-231. https://doi.org/10.4103/1008-682X.122365

14. Carrageta, D. F., Oliveira, P. F., Alves, M. G., \& Monteiro, M. P. Obesity and male hypogonadism: Tales of a vicious cycle. Obesity Reviews. 2019; 20(8):1148-1158. https://doi.org/10.1111/obr.12863

15. Kelly D.M., Jones T.H. Testosterone and obesity. Obesity Reviews. 2015; 16(7):581-606 doi: 10.1111/obr.12282 PMID: 25982085

16. Fernandez, C. J., Chacko, E. C., \& Pappachan, J. M. Male obesity-related secondary hypogonadism - pathophysiology, clinical implications and Management. In European Endocrinology. 2019; 15(2):83-90. https://doi.org/10.17925/EE.2019.15.2.83

17. Aguirre, L. E., Colleluori, G., Fowler, K. E., Jan, I. Z., Villareal, K., Qualls, C., Robbins, D., Villareal, D. T., \& Armamento-Villareal, R. High aromatase activity in hypogonadal men is associated with higher spine bone mineral density, increased truncal fat and reduced lean mass. European Journal of Endocrinology. 2015; 173(2):167-174. https://doi.org/10.1530/EJE-14-1103

18. Merlotti, D., Gennari, L., Stolakis, K., \& Nuti, R. (2011). Aromatase Activity and Bone Loss in Men. Journal of Osteoporosis. 2011; 1-11. https://doi.org/10.4061/2011/230671

19. Colleluori, G., Chen, R., Turin, C. G., Vigevano, F. et al. Aromatase Inhibitors Plus Weight Loss Improves the Hormonal Profile of Obese Hypogonadal Men Without Causing Major Side Effects. Frontiers in Endocrinology. 2020; 11:277. https://doi.org/10.3389/ fendo.2020.00277

20. Haring, R., Baumeister, S. E., Völzke, H., Dörr, M., Felix, S. B., Kroemer, H. K., Nauck, M., \& Wallaschofski, H. Prospective association of low total testosterone concentrations with an adverse lipid profile and increased incident dyslipidemia. European Journal of Preventive Cardiology. 2011; 18(1):86-96. https://doi.org/10.1097/HJR.0b013e32833c1a8d

21. Kersten Sander. Physiological regulation of lipoprotein lipase. Biochim Biophys Acta. 2014; 1841(7):919-933. doi: 10.1016/j. bbalip.2014.03.013.

22. Andrade Junior, M. C. de. Lipoprotein Lipase: A General Review. Insights in Enzyme Research. 2018; 02(01):1-13. https://doi. org/10.21767/2573-4466.100013

23. Davies, B. S. J., Beigneux, A. P., Fong, L. G., \& Young, S. G. (2012). New wrinkles in lipoprotein lipase biology. Current Opinion in Lipidology. 2012; 23(1):35-42. NIH Public Access. https://doi.org/10.1097/MOL.0b013e32834d0b33

24. Fui, M. N. T., Dupuis, P., \& Grossmann, M. Lowered testosterone in male obesity: Mechanisms, morbidity and management. Asian $J$ Androl. 2014; 16(2):223-231. https://doi.org/10.4103/1008-682X.122365

25. Lee, M. J., Chien, K. L., Chen, M. F., Stephenson, D. A., \& Su, T. C. Overweight modulates APOE and APOA5 alleles on the risk of severe hypertriglyceridemia. Clinica Chimica Acta. 2013; 416:31-35. https://doi.org/10.1016/j.cca.2012.10.054

26. Adieva M.K.,Aukenov N.E., Kazymov M.S., NurzhanovaA.E., Slamkhanova N.S., Masabaeva M.R. Influence of LPL gene polymorphism on insulin resistance among adolescents from Semey, East Kazakhstan region. VESTNIK KAZAHSKOGO NASIONALNOGO MEDISINSKOGO UNIVERSITETA. 2021; 2-1 372-376. https://elibrary.ru/item.asp?id=44787086

27. Das, B., Pawar, N., Saini, D., \& Seshadri M. Genetic association study of selected candidate genes (ApoB, LPL, Leptin) and telomere length in obese and hypertensive individuals. BMC Medical Genetics. 2009; 10(1):99. https://doi.org/10.1186/1471-2350-10-99

28. Hamosh, M., \& Hamosh, P. Lipoproteins and Lipoprotein Lipase. Comprehensive Physiology. 2011; 387-418. John Wiley \& Sons, Inc. https://doi.org/10.1002/cphy.cp030112

29. Ohlsson, C., Wallaschofski, H., Lunetta, K. L., Stolk, L., Perry, J. R. B., Koster, A. et al. Genetic Determinants of Serum Testosterone Concentrations in Men. PLoS Genetics. 2011; 7(10):e1002313. https://doi.org/10.1371/journal.pgen.1002313 
30. Coviello, A. D., Haring, R., Wellons, M., Vaidya, D., Lehtimäki, T., Keildson, S. et al. A genome-wide association meta-analysis of circulating sex hormone-binding globulin reveals multiple loci implicated in sex steroid hormone regulation. PLoS Genetics. 2012; 8(7):1-12. https://doi.org/10.1371/journal.pgen.1002805

31. Yassin, D. J., Doros, G., Hammerer, P. G., \& Yassin, A. A. Long-term testosterone treatment in elderly men with hypogonadism and erectile dysfunction reduces obesity parameters and improves metabolic syndrome and health-related quality of life. Journal of Sexual Medicine. 2014; 11(6):1567-1576. https://doi.org/10.1111/jsm.12523

32. Vandenput, L., \& Ohlsson, C. Genome-wide association studies on serum sex steroid levels. Molecular and Cellular Endocrinology. 2014; 382(1):758-766. https://doi.org/10.1016/j.mce.2013.03.009

33. Chen, Y. P., Nie, L. L., Li, H. G., Liu, T. H., Fang, F., Zhao, K. et al. The rs5934505 single nucleotide polymorphism (SNP) is associated with low testosterone and late-onset hypogonadism, but the rs 10822184 SNP is associated with overweight and obesity in a Chinese Han population: A case-control study. Andrology. 2016; 4(1):68-74. https://doi.org/10.1111/andr.12127

34. Castellano-Castillo, D., Royo, J. L., Martínez-Escribano, A., Sánchez-Alcoholado, L., Molina-Vega, M., Queipo-Ortuño, M. I. et al. Effects of SHBG rs 1799941 Polymorphism on Free Testosterone Levels and Hypogonadism Risk in Young Non-Diabetic Obese Males. Journal of Clinical Medicine. 2019; 8(8):1136. https://doi.org/10.3390/jcm8081136

35. Jin, G., Sun, J., Kim, S. T., Feng, J., Wang, Z., Tao, S., Chen, Z., Purcell, L. et al. Genome-wide association study identifies a new locus JMJD1C at 10q21 that may influence serum androgen levels in men. Human Molecular Genetics. 2012; 21(23):5222-5228. https:// doi.org/10.1093/hmg/dds361

36. Grigorova, M., Punab, M., Poolamets, O., Adler, M., Vihljajev, V., \& Laan, M. Genetics of sex hormone-binding globulin and testosterone levels in fertile and infertile men of reproductive age. Journal of the Endocrine Society. 2017; 1(6):560-576. https://doi.org/10.1210/ js.2017-00050

37. Goto, A., Morita, A., Goto, M., Sasaki, S., Miyachi, M., Aiba, N., Terauchi, Y., Noda, M., \& Watanabe, S. Associations of sex hormonebinding globulin and testosterone with diabetes among men and women (the Saku Diabetes study): A case control study. Cardiovascular Diabetology. 2012; 11. https://doi.org/10.1186/1475-2840-11-130

38. Shakhanova, A., Aukenov, N., Nurtazina, A., Massabayeva, M., Babenko, D., Adiyeva, M., \& Shaimardonov, N. Association of polymorphism genes LPL, ADRB 2, agt and agtr1 with risk of hyperinsulinism and insulin resistance in the kazakh population. Biomedical Reports. 2020; 13(5):1-10. https://doi.org/10.3892/br.2020.1342

39. Shaw, J. E., Sicree, R. A., \& Zimmet, P. Z. Global estimates of the prevalence of diabetes for 2010 and 2030. Diabetes Research and Clinical Practice. 2010; 87(1):4-14. https://doi.org/10.1016/j.diabres.2009.10.007

40. Perry, J. R. B., Weedon, M. N., Langenberg, C., Jackson, A. U., Lyssenko, V. et al. Genetic evidence that raised sex hormone binding globulin (SHBG) levels reduce the risk of type 2 diabetes. Human Molecular Genetics. 2010; 19(3):535-544. https://doi.org/10.1093/ hmg/ddp522

41. Herder, C., \& Roden, M. Genetics of type 2 diabetes: Pathophysiologic and clinical relevance. Eur J Clin. 2011; 41(6): 679-692. https:// doi.org/10.1111/j.1365-2362.2010.02454.x

42. Wallace, I. R., McKinley, M. C., Bell, P. M., \& Hunter, S. J. Sex hormone binding globulin and insulin resistance. Clin. Endocrinology. 2013; 78(3):321-329. https://doi.org/10.1111/cen.12086

43. El Tarhouny, S., Zakaria, S., Abdu-Allah, A., Hadhoud, K., Hanafi, M., \& Al Nozha ArBIM, O. Sex Hormone Binding Globulin Gene Polymorphism and Risk of Type 2 Diabetes Mellitus in Egyptian Men. West Indian Med J. 2015; 64(4):338-343. doi: 10.7727/ wimj.2014.088.

44. 44. Völzke, H., Aumann, N., Krebs, A., Nauck, M., Steveling, A., Lerch, M. M., Rosskopf, D., \& Wallaschofski, H. Hepatic steatosis is associated with low serum testosterone and high serum DHEAS levels in men. International Journal of Andrology. $2010 ; 33(1)$ :45-53. https://doi.org/10.1111/j.1365-2605.2009.00953.x

45. Wang, Q., Kangas, A. J., Soininen, P., Tiainen, M., Tynkkynen, T. et al. Sex hormone-binding globulin associations with circulating lipids and metabolites and the risk for type 2 diabetes: observational and causal effect estimates. International Journal of Epidemiology.2015; 44(2):623-637. https://doi.org/10.1093/ije/dyv093

46. Le, T. N., Nestler, J. E., Strauss, J. F., \& Wickham, E. P. Sex hormone-binding globulin and type 2 diabetes mellitus. Trends in Endocrinology and Metabolism. 2012; 23(1):32-40. https://doi.org/10.1016/j.tem.2011.09.005

47. Yeap, B. B., Beilin, J., Shi, Z., Knuiman, M. W., Olynyk, J. K., Chubb, S. A. P., Bruce, D. G., \& Milward, E. A. The C282Y polymorphism of the hereditary hemochromatosis gene is associated with increased sex hormone-binding globulin and normal testosterone levels in men. Journal of Endocrinological Investigation. 2010; 33(8):544-548. https://doi.org/10.1007/bf03346645

48. Ramachandran, S., Hackett, G. I., \& Strange, R. C. Sex Hormone Binding Globulin: A Review of its Interactions With Testosterone and Age, and its Impact on Mortality in Men With Type 2 Diabetes. Sexual Medicine Reviews. 2019; 7(4):669-678). https://oi. org/10.1016/j.sxmr.2019.06.006

49. Shahid, S. U., Shabana, \& Rehman, A. Predictive value of plasma lipid levels for coronary artery disease (CAD). Biologia. 2020; 75(9):1455-1463. https://doi.org/10.2478/s11756-020-00448-4

50. Topolyanskaya, S. V., Vakulenko, O. N., Eliseeva, T. A., Balyasnikova, N. A., Kalinin, G. A., Kupina, L. M., \& Strizhova, N. V. Lipid blood profile in old patients with ischemic heart disease. Kardiologiya. 2018; 58(3):28-36. https://doi.org/10.18087/cardio.2018.3.10095

51. Dedov I.I., Tyulpakov A.N., Chekhonin V.P., Baklaushev V.P., Archakov A.I., Moshkovsky S.A. Personalized medicine: current state and prospects. Bulletin of the RAMS.2012; 67(12):4-12. https://doi.org/10.15690/vramn.v67i12.474

52. Sentsova T.B., Kirillova O.O., Tutelyan V.A., Vorozhko I.V., Revyakina V.A., Gapparova K.M. Immunology. 2014; 5 (35):241-244.

53. Sentsova T.B., Chernyak O.O., Vorozhko I.V., Gapparova K.M., Grigoryan O.N., Chekhonina Yu.G., Churicheva A.M. Genetic predictors of the effectiveness of standard low-calorie diet therapy in obese patients. Obesity and Metabolism. 2016; 13(3):45-48. https://doi.org/10.14341/omet2016345-48

54. Pyun, J.-A., Kim, S., Park, K., Baik, I., Cho, N. H., Koh, I. et al. Interaction Effects of Lipoprotein Lipase Polymorphisms with Lifestyle on Lipid Levels in a Korean Population: A Cross-sectional Study. Genomics \& Informatics. 2012; 10(2):88-98. https://doi.org/10.5808/ gi.2012.10.2.88

55. Baik, I., Lee, S. K., Kim, S. H., \& Shin, C. A lipoprotein lipase gene polymorphism interacts with consumption of alcohol and unsaturated fatto modulate serum hdl-cholesterol concentrations. Journal of Nutrition. 2013; 143(10):1618-1625. https://doi.org/10.3945/ jn. 113.175315 
56. Han, P., Wei, G., Cai, K., Xiang, X., Deng, W. P., Li, Y. B., Kuang, S. et al. Identification and functional characterization of mutations in LPL gene causing severe hypertriglyceridaemia and acute pancreatitis. Journal of Cellular and Molecular Medicine. 2020; 24(2):1286-1299. https://doi.org/10.1111/jcmm.14768

57. Lun, Y., Sun, X., Wang, P., Chi, J., Hou, X., \& Wang, Y. Severe hypertriglyceridemia due to two novel loss-of-function lipoprotein lipase gene mutations (C310R/E396V) in a Chinese family associated with recurrent acute pancreatitis. Oncotarget. 2017; 8(29):4774147754. https://doi.org/10.18632/oncotarget.17762

58. Pingitore, P., Lepore, S. M., Pirazzi, C., Mancina, R. M., Motta, B. M., Valenti, L., Berge, K. E., Retterstøl, K., Leren, T. P., Wiklund, O., \& Romeo, S. Identification and characterization of two novel mutations in the LPL gene causing type I hyperlipoproteinemia. Journal of Clinical Lipidology. 2016; 10(4):816-823. https://doi.org/10.1016/j.jacl.2016.02.015

59. Xie, S.-L., Chen, T.-Z., Huang, X.-L., Chen, C., Jin, R., Huang, Z.-M., \& Zhou, M.-T. Genetic Variants Associated with Gestational Hypertriglyceridemia and Pancreatitis. PLoS ONE. 2015; 10(6):e0129488. https://doi.org/10.1371/journal.pone.0129488

60. Chen, T. Z., Xie, S. L., Jin, R., \& Huang, Z. M. A novel lipoprotein lipase gene missense mutation in Chinese patients with severe hypertriglyceridemia and pancreatitis. Lipids in Health and Disease. 2014; 13(1): 52. https://doi.org/10.1186/1476-511X-13-52

61. Richards, S., Aziz, N., Bale, S., Bick, D., Das, S., Gastier-Foster, J., Grody, W. W., Hegde, M., Lyon, E., Spector, E., Voelkerding, K., \& Rehm, H. L. Standards and guidelines for the interpretation of sequence variants: A joint consensus recommendation of the American College of Medical Genetics and Genomics and the Association for Molecular Pathology. Genetics in Medicine. 2015; 17(5):405-424. https://doi.org/10.1038/gim.2015.30

62. Johansen, C. T., \& Hegele, R. A. Genetic bases of hypertriglyceridemic phenotypes. In Current Opinion in Lipidology . 2011; 22 (4): 247-253. https://doi.org/10.1097/MOL.0b013e3283471972

63. Khovidhunkit, W., Charoen, S., Kiateprungvej, A., Chartyingcharoen, P., Muanpetch, S., \& Plengpanich, W. Rare and common variants in LPL and APOA5 in thai subjects with severe hypertriglyceridemia: A resequencing approach. Journal of Clinical Lipidology. 2016; 10(3):505-511.e1. https://doi.org/10.1016/j.jacl.2015.11.007

64. Gaudet, D., Méthot, J., \& Kastelein, J. Gene therapy for lipoprotein lipase deficiency. In Current Opinion in Lipidology . 2012; 23( 4):310-320. https://doi.org/10.1097/MOL.0b013e3283555a7e

65. Rebhi, L., Kchok, K., Omezzine, A., Kacem, S., Rejeb, J. et al. Six lipoprotein lipase gene polymorphisms, lipid profile and coronary stenosis in a Tunisian population. Molecular Biology Reports. 2012; 39(11):9893-9901. https://doi.org/10.1007/s11033-012-1856-9

66. 66. DAOUD, M. S., ATAYA, F. S., FOUAD, D., ALHAZZANI, A., SHEHATA, A. I., \& AL-JAFARI, A. A. Associations of three lipoprotein lipase gene polymorphisms, lipid profiles and coronary artery disease. Biomedical Reports.2013; 1(4):573-582. https://doi. org/10.3892/br.2013.126

67. Sarzynski, M. A., Jacobson, P., Rankinen, T., Carlsson, B., Sjöström, L., Carlsson, L. M. S., \& Bouchard, C. Association of GWASBased Candidate Genes with HDL-Cholesterol Levels before and after Bariatric Surgery in the Swedish Obese Subjects Study. The Journal of Clinical Endocrinology \& Metabolism. 2011; 96(6):E953-E957. https://doi.org/10.1210/jc.2010-2227

68. Božina, T., Sertić, J., Lovrić, J., Jelaković, B., Šimić, I., \& Reiner, Ž. Interaction of genetic risk factors confers increased risk for metabolic syndrome: The role of peroxisome proliferator-Activated receptor $\gamma$. Genetic Testing and Molecular Biomarkers. 2014; 18(1):32-40. https://doi.org/10.1089/gtmb.2013.0344

69. Kim, Y., Lee, M., Lim, Y., Jang, Y., Park, H. K., \& Lee, Y. (2013). The gene-diet interaction, LPL PvuII and HindIII and carbohydrate, on the criteria of metabolic syndrome: KMSRI-Seoul Study. Nutrition. 2013; 29(9):1115-1121. https://doi.org/10.1016/j.nut.2013.02.014

70. Gao, R. R., Wang, M., Hu, Y., Xu, C. Y., Li, Y. C., Zhang, Z. Y., Chen, S. Y., \& Mao, X. Y. Impact of LPL gene rs 283 polymorphism on exercise-induced changes in metabolism of obese adolescents and the regulatory mechanisms behind it. Experimental Physiology. 2015; 100(6):698-707. https://doi.org/10.1113/EP085127 